University of Massachusetts Amherst

ScholarWorks@UMass Amherst

1999

\title{
Characterization of selenium species in biological extracts by enhanced ion-pair liquid chromatography with inductively coupled plasma- mass spectrometry and by referenced electrospray ionization-mass spectrometry
}

M Kotrebai

SM Bird

JF Tyson

E Block

PC Uden

Follow this and additional works at: https://scholarworks.umass.edu/chem_faculty_pubs

\section{Recommended Citation}

Kotrebai, M; Bird, SM; Tyson, JF; Block, E; and Uden, PC, "Characterization of selenium species in biological extracts by enhanced ion-pair liquid chromatography with inductively coupled plasma-mass spectrometry and by referenced electrospray ionization-mass spectrometry" (1999). SPECTROCHIMICA ACTA PART B-ATOMIC SPECTROSCOPY. 1053.

Retrieved from https://scholarworks.umass.edu/chem_faculty_pubs/1053 


\title{
Characterization of selenium species in biological extracts by enhanced ion-pair liquid chromatography with inductively coupled plasma-mass spectrometry and by referenced electrospray ionization-mass spectrometry
}

\author{
Mihály Kotrebai ${ }^{\mathrm{a}}$, Susan M. Bird ${ }^{\mathrm{a}}$, Julian F. Tyson ${ }^{\mathrm{a}}$, Eric Block ${ }^{\mathrm{b}}$, \\ Peter C. Uden ${ }^{\mathrm{a}, *}$ \\ ${ }^{a}$ Department of Chemistry, Lederle Graduate Research Tower A, University of Massachusetts, Box 35410, Amherst, \\ MA 01003-4510, USA \\ ${ }^{\mathrm{b}}$ Department of Chemistry, SUNY-Albany, Albany, NY 12222, USA
}

Received 26 January 1999; accepted 17 June 1999

\begin{abstract}
Selenium is an essential nutrient for humans; selenium compounds catalyze intermediate metabolism reactions and inhibit the toxic effects of heavy metals such as arsenic, cadmium and mercury. Some extracts of seleniumenriched biological materials show cancer preventive effects, tentatively attributable to the biological functions of selenoamino acids. An improved ion pair chromatographic method with methodological enhancements for the separation, qualitative and quantitative determination of non-volatile selenium compounds extracted from different samples has been developed using ICP-MS as an element-selective detector. Separation power early in the chromatogram was increased to baseline separation in the standard mixture as a result of decreasing spray chamber size from 97 to $14 \mathrm{ml}$, and increasing trifluoracetic acid (TFA) concentration in the mobile phase from 0.1 to $0.6 \%$. The former $\mathrm{pH}$ was restored by the addition of ammonia to the mobile phase, which also served to increase the column recovery of inorganic anions. Calibration curves for different selenoamino acids showed statistically different behavior. Biological sample extracts were characterized using HPLC-ICP-MS. Mass spectral behavior of selenoamino acids, using electrospray and ion trap technology with direct infusion and liquid chromatographic sample introduc-tion, is also reported.
\end{abstract}




\section{Introduction}

It has been observed clinically that extracts of several selenium-enriched biological materials have cancer-preventive effects, tentatively attributable to the biological functions of selenoamino acids [1-3]. Numerous organoselenium compounds have been identified in biological samples. In organisms such as marine bacteria and plankton, selenium exists predominantly as selenoamino acids in proteins [4]. In other organisms selenium may occur in a nonprotein form, non-covalently associated with proteins. Several biochemical cycles which link inorganic selenium compounds with simple methylated, and more complex organic selenium compounds, have been proposed $[5,6]$.

People are exposed to selenium mainly through their diet. Selenoamino acids are the principle dietary form of selenium, being absorbed to a greater extent than inorganic species. The major compounds are selenomethionine (found in plants such as soybean, wheat and yeast) and selenocysteine (present in animal proteins). Selenocystine was identified in corn, and some methylated derivatives (selenocystathionine, selenohomocysteine) were reported in selenium-accumulating plants [7,8]. Free selenomethionine and selenized yeast are present in the formulation of several nutritional supplements. Dietary selenium supplementation is a popular health fad, with largely unsubstantiated claims being made for the prevention of angina, arthritis, cerebrovascular disease, aging, infections, infertility, and so forth. There is a need for more reliable methods to determine different selenium species, thus increasing the understanding of their biochemical pathways and plant metabolism.

When chromatographic separation is used, ana- lytes must be extracted from any solid samples prior to the identification and determination of the selenium species. Free selenoamino acids can be extracted with water, whereas hydrolysis is necessary for selenoamino acids incorporated into protein. Hydrolysis is commonly performed using $6 \mathrm{M} \mathrm{HCl}$ at $110^{\circ} \mathrm{C}$, but degradation of selenium compounds has already been noted upon using this procedure [9]. Enzymatic hydrolysis, using 'Protease XIV', leads to improved extraction efficiencies compared to simple water extraction [7]. We have reported on the extraction of selenium compounds and examination of the selenium mass balance throughout the extraction procedure [6].

The determination of selenium species by high performance liquid chromatography (HPLC) offers a number of potential benefits. These include minimal preparation of liquid samples, and separation at ambient temperatures, thus avoiding the risk of thermal decomposition of labile compounds. Selenium species have been separated by several chromatographic modes, including normal- and reversed-phase partitioning, ionpairing and ion-exchange [7,10-13]. Reversed phase chromatography is often used with ion-pairing reagents [7,14-16].

Current HPLC methodology for selenium compounds employs electrochemical [17], UV [10], fluorometric [18], or atomic spectroscopic detection $[7,11,19]$. The first three detection methods suffer from numerous interferences from the sample and reagents. The application of selenium-specific spectroscopic detectors such as atomic absorption spectroscopy (AAS) [7], inductively coupled plasma-optical emission spectroscopy (ICP-OES) [11], and inductively coupled plasma-mass spectrometry (ICP-MS) [19] are helpful in eliminating these interferences. 
The HPLC-ICP-MS connection is very simple, as the LC eluent is simply coupled to the nebulizer of the plasma source. In the optimization of a chromatographic method, an important requirement is to minimize extra-column broadening. The sample introduction device of an atomic spectroscopic detector is responsible for the majority of the extra-column broadening due to its substantial dead volume resulting in loss of resolution. A more suitable interface is needed in order to achieve higher separation efficiency. This high efficiency coupling can be done using direct injection nebulizers [20,21]. The price of these devices and the necessary changes in HPLC hardware (low flow pump, micro-injection valve, narrow bore column) precludes their widespread use. The sub-optimal approach is the use of miniaturized spray chambers [22]. The transport efficiencies of a double pass spray chamber with different cyclone type spray chambers were compared by Rivas et al. [23]. In the study described herein, we have used a miniaturized spray chamber with an impact bead design as an alternative to the double pass spray chamber supplied with the ICP-MS instrument.

A plasma source mass spectrometer as an HPLC detector imposes limitations on the performance of the method. The viable organic solvent content of the mobile phase is limited unless solvent removal is used. However, since solventremoving devices may cause peak broadening, they are best avoided. The practical limit for methanol in the mobile phase was found to be $5 \%$ under which condition the PE-Elan 5000 instrument can run for an extended period without undue contamination. In general, the organic content of the mobile phase should be at the viable chromatographic minimum.

Molecular mass spectroscopy of amino acids is the subject of extensive publication [24,25]. In recent years the focus of research has been on peptides and their composition, with few investigators studying the fragmentation properties of single amino acids. Selenoamino acids have been examined by MS [26-28], but the use of the electrospray-ion trap combination for such studies has not been reported.

\section{Experimental}

\subsection{Instrumentation}

An Elan 5000 inductively coupled plasma mass spectrometer (Perkin-Elmer Sciex, Thornhill, Ontario, Canada) was used for total selenium determination and as the detector for HPLCICP-MS. Samples were introduced using a cross flow nebulizer with a Scott type double pass spray chamber, or a Meinhard nebulizer with two different spray chambers containing impact beads made in house. The smaller of the in house fabricated spray chambers is shown in Fig. 1. The spray chambers had path lengths of $24,8.4$ and $8.4 \mathrm{~cm}$, and volumes of 97,34 and $14 \mathrm{ml}$, respectively. The ICP-MS parameter settings were as follows: forward power $1003 \mathrm{~W}$; plasma Ar flow $151 / \mathrm{min}$; auxiliary Ar flow $0.81 / \mathrm{min}$; nebulizer flow $0.860-1.0601 / \mathrm{min}$ (optimized daily); nickel sampler and skimmer cones; normal resolution; peak hop mode; and dwell time $250 \mathrm{~ms}$. The selenium signal at $m / z=82$ was monitored without krypton correction, and ${ }^{72} \mathrm{Ge}$ was used as internal standard.

The chromatographic system consisted of a liquid chromatographic pump (SP88100, SpectraPhysics, San Jose, Ca, USA) and a Zorbax SB-C8 column $(4.6 \mathrm{~mm} \times 15 \mathrm{~cm})$, preceded by a Zorbax SB-C8 guard column $(4.0 \mathrm{~mm} \times 12.5 \mathrm{~mm})(\mathrm{MAC}-$ MOD Analytical, Chadds Ford, PA, USA), or a $5-\mu \mathrm{m}$ Symmetry Shield RP8 $(3.9 \mathrm{~mm} \times 15 \mathrm{~cm})$ column (Waters Corporation, Milford, MA, USA).

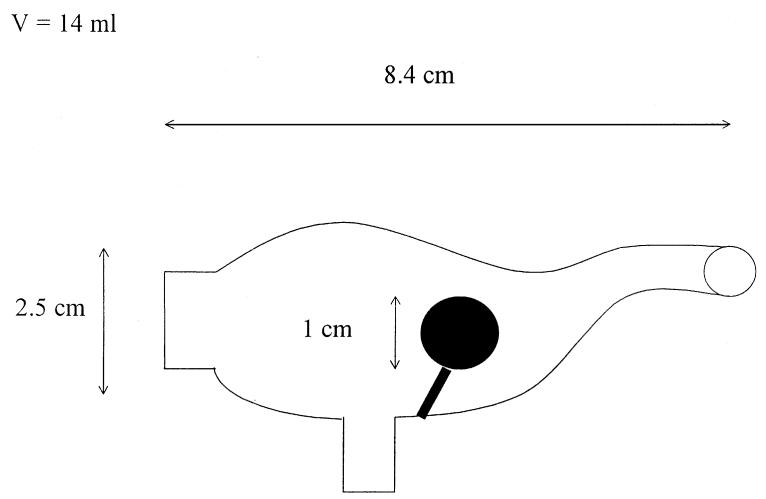

Fig. 1. Diagram of the small impact bead spray chamber. 
The column was connected to the nebulizer with PEEK $^{\circledR}$ tubing $(30 \mathrm{~cm} \times 0.25 \mathrm{~mm}$ i.d. $)$. The optimized mobile phase composition for the Zorbax column was $98 / 2$ (v/v) water/methanol with $0.1 \%$ trifluoroacetic acid [15]. The mobile phase composition for the Symmetry Shield column was $99 / 1(\mathrm{v} / \mathrm{v})$ water/methanol with $0.6 \%$ trifluoroacetic acid, containing enough concentrated $\mathrm{NH}_{4} \mathrm{OH}$ to set the $\mathrm{pH}$ to 2 (typically $7-7.5 \mathrm{ml}$ ammonia per $1000 \mathrm{ml}$ mobile phase). Germanium internal standard, at $25 \mathrm{ng} / \mathrm{ml}$ concentration was also added to the mobile phase. The mobile phase flow rate was $1.0 \mathrm{ml} / \mathrm{min}$ and the sample injection volume was $10 \mu \mathrm{l}$.

A Bruker Esquire-LC Mass Spectrometer (Bruker-Franzen Analytik Gmbh, Bremen, Germany) was used for the molecular mass spectral studies. For the analysis of standard materials, the samples were infused to the electrospray ionization (ESI) source at a flow rate of $1-2 \mu \mathrm{l} / \mathrm{min}$. For HPLC-MS analysis the flow rate was decreased from the original $1 \mathrm{ml} / \mathrm{min} \mathrm{LC}$ flow rate to $0.5 \mathrm{ml} / \mathrm{min}$. For the MS analysis only the Symmetry Shield column was used with a $20-\mu 1$ injection loop. The column was connected to the ESI source with PEEK ${ }^{\circledR}$ tubing $(8 \mathrm{~cm} \times 0.25 \mathrm{~mm}$ i.d.). Mass calibration and the optimization of the operating parameters were done daily and generally followed the manufacturer's guidelines.

\subsection{Chemicals}

Barnstead E-pure $18 \mathrm{M} \Omega$ water (Boston, MA USA), nitric acid, hydrochloric acid (purified by sub-boiling) and ammonium hydroxide (Certified ACS Plus, Fisher, Fair Lawn, New Jersey, USA), trifluoroacetic acid (Aldrich, Milwaukee, WI, USA) and methanol (HPLC grade) were used.

Sodium selenate, sodium selenite, DL-selenomethionine, DL-selenoethionine, DL-selenocystine, and Protease XIV, were obtained from Sigma (St. Louis, MO, USA). Se-methyl-DL-selenocysteine, $S e$-1-propyl-DL-selenocysteine, and $S e$-allyl-DLselenocysteine were obtained from Dr Howard Ganther (University of Wisconsin, Madison, WI, USA), cis / trans-Se-1-propenyl-DL-selenocysteine, $\mathrm{Se}$-2-methyl-2-propenyl-DL-selenocysteine, $\mathrm{Se}$-2propynyl-DL- selenocysteine, Se-1-methyl-2-pro-
penyl-DL-selenocysteine and $\gamma$-glutamyl-Semethyl-L-selenocysteine were synthesized inhouse. Plasma selenium and germanium standard solutions $(1000 \mu \mathrm{g} / \mathrm{ml})$ were obtained from Spex (Spex Industries Inc., Edison, New Jersey, USA). Selenium-enriched yeast was obtained from Nutrition 21 (San Diego, CA, USA), Dr. Helen Crews (Norfolk and Norwich Hospital, Norwich England), and Dr Richard Zitomer (State University of New York, Albany, NY, USA). Phytoremediation samples of Se-accumulator plants, Brassica juncea, Astragalus praelongus, and alfalfa without selenium were obtained from Gary S. Bañuelos (USDA, Fresno, CA, USA). Phytoplankton $(3 \mathrm{H})$ was obtained from Gary Wickfors (National Marine Fisheries Service, Milford, CT, USA). Commercially available selenium supplements were obtained locally. Stock solutions of selenoamino acids were prepared in $0.2 \mathrm{M} \mathrm{HCl}$. A stock solution of selenate was prepared in $2 \%$ (v/v) $\mathrm{HNO}_{3}$, while the Spex selenium standard was used as a stock solution of selenite. All solutions were stored in the dark at $0-4^{\circ} \mathrm{C}$.

\subsection{Sample preparation}

\subsubsection{Total selenium determination and extractions}

The determination of total selenium and efficiencies of enzymatic and hot water extractions for ICP-MS analysis followed the procedures reported earlier [6], and they are only briefly summarized here.

For the total selenium determination $0.1-0.2 \mathrm{~g}$ of sample was measured into a microwave vessel. Distilled concentrated $\mathrm{HNO}_{3}(5 \mathrm{ml})$ and $1 \mathrm{ml} 2.5$ $\mu \mathrm{g} / \mathrm{g}$ Ge internal standard were added to each sample, then the vessels were covered and left overnight. The next day $2 \mathrm{ml}$ concentrated $\mathrm{H}_{2} \mathrm{O}_{2}$ and $2 \mathrm{ml}$ water was added to the sample which was then digested using a high-pressure closedvessel microwave digestion system. The digested samples were transferred to $50-\mathrm{ml}$ centrifuge tubes and diluted with $18 \mathrm{M} \Omega$ water to $25 \mathrm{ml}$ total volume. Selenium was determined in the resulting solutions by the method of standard additions.

For the hot water extraction, $5 \mathrm{ml}$ distilled de-ionized water was added to $0.2 \mathrm{~g}$ sample in a 
15-ml centrifuge tube and the tube was placed in a double-boiling water bath for $1 \mathrm{~h}$. The mix was shaken well every $15 \mathrm{~min}$. For the enzymatic extraction, $5 \mathrm{ml}$ distilled de-ionized water was added to $0.2 \mathrm{~g}$ sample and $0.02 \mathrm{~g}$ 'Protease XIV' enzyme in a $15-\mathrm{ml}$ centrifuge tube, then the mixture was shaken for $24 \mathrm{~h}$ at room temperature. After the extraction the samples were centrifuged and filtered.

\subsubsection{Preparation of standards for MS analysis}

Standard solid materials were dissolved in a $48.5 / 48.5 / 3(\mathrm{v} / \mathrm{v})$ methanol/water/acetic acid mixture. From the solutions, which were already in $0.2 \% \mathrm{HCl}, 1 \mathrm{ml}$ was dried under vacuum, and then dissolved in the methanol/water/acetic acid mixture. Solutions were also prepared by simply diluting the $0.2 \% \mathrm{HCl}$ solution twofold with $94 / 6$ (v/v) methanol/acetic acid solution. The injected selenium standards were in the $10-100 \mu \mathrm{g} / \mathrm{ml}$ range.

\subsection{Chromatographic experiments}

\subsubsection{Spray chamber modification}

The effect of spray chamber design on the resolution of early eluting peaks in a standard chromatogram was studied. The spray chamber volume was decreased from $97 \mathrm{ml}$ to $14 \mathrm{ml}$ in two steps. The resolution $(R)$ was calculated using Peakfit ${ }^{\mathrm{TM}}$ software.

\subsubsection{Chromatographic conditions}

The effect on the chromatographic separation of selenium-containing molecules due to changes in stationary phase, ion-pairing concentration, methanol content, and $\mathrm{pH}$ control by ammonia addition, was studied. The TFA concentration was varied in the range of $0.1-0.6 \%(\mathrm{v} / \mathrm{v})$. The methanol concentration was varied between 5 and $1 \%(\mathrm{v} / \mathrm{v})$. The $\mathrm{pH}$ was adjusted between 1.86 and 2.24 .

\subsubsection{Calibration}

Calibration curves for different selenoamino acids were recorded and the role of germanium as an internal standard in the mobile phase was explored. Five-point calibration curves with four replicates per point were prepared for seven selenoamino acid standards. Selenoamino acid standard concentrations ranged from $140 \mathrm{ng} / \mathrm{ml}$ to $10 \mu \mathrm{g} / \mathrm{ml}$ selenium. Calibrations curves were obtained by plotting integrated peak areas vs. selenium concentration. The $95 \%$ confidence intervals ( $n-2$ degrees of freedom) were calculated from the standard error of the slope and standard error of the intercept. Curves were fit using Statview 4.5 software. Integration and other chromatographic calculations were done using Peakfit ${ }^{\mathrm{TM}}$ software. Separate peak height based calibration curves were used to calculate instrumental limits of detection (LOD) and limits of quantification (LOQ) by plotting peak heights vs. selenium concentration.

\subsubsection{Sample analysis by HPLC-ICP-MS}

Natural sample extracts were analyzed using HPLC-ICP-MS after hot water or enzymatic extractions. Integration and other chromatographic calculations were done using Peakfit ${ }^{\mathrm{TM}}$ software. The \pm intervals reflect $95 \%$ confidence intervals based on 3-5 measurements. Column recovery percentages were calculated by dividing the total area of the chromatogram by the flow injection peak area for the same sample $(n=3)$.

\subsubsection{Standard analysis by ESI-MS and HPLC- ESI-MS}

ESI-MS was used to study fragmentation properties of standard selenoamino acids and HPLC-ESI-MS was used to record chromatograms of standard mixtures. The main drawback with ESI-MS has proven to be limited sensitivity; the ESI-MS exhibiting 2-3 orders of magnitude less sensitivity than the ICP-MS.

\section{Results and discussion}

\subsection{Chromatographic improvements due to spray chamber design}

The original double pass spray chamber had an internal volume of $97 \mathrm{ml}$, which causes considerable extra column broadening. For this experiment, impact bead type spray chambers were 


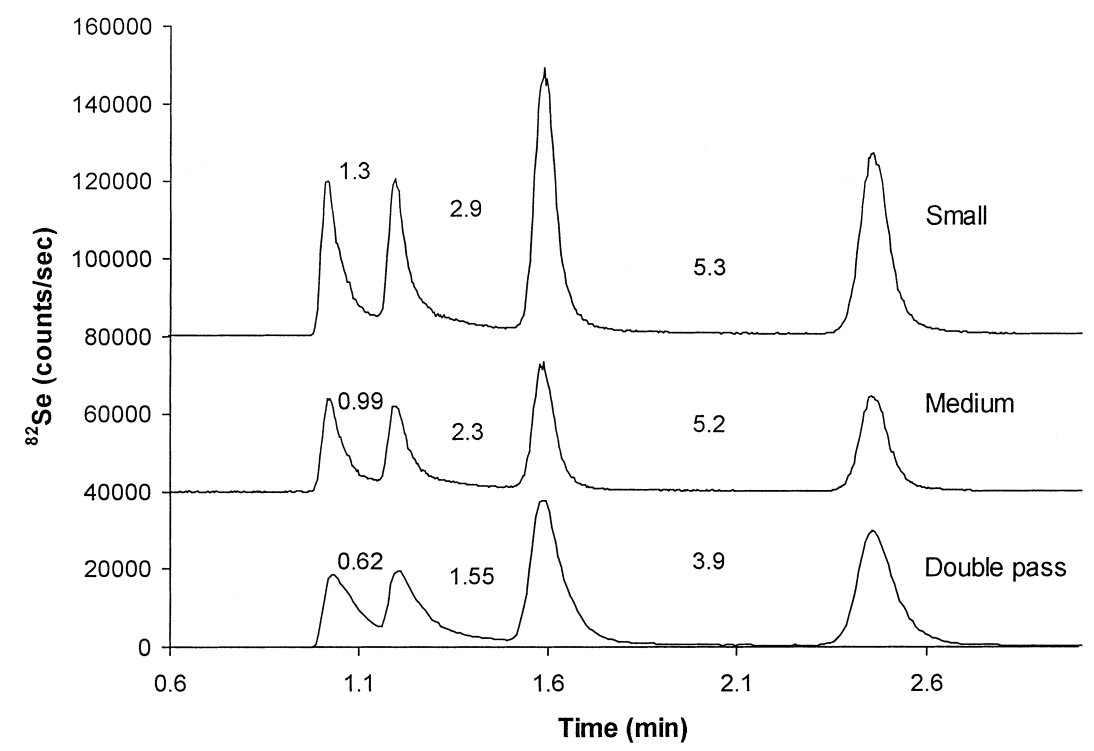

Fig. 2. The effect of spray chamber size on the resolution between selenate and selenite (first pair), selenite and selenocystine (second pair), and selenocystine and Se-methyl-DL-selenocysteine (third pair) using the Waters Symmetry Shield column (resolution values are indicated between the respective peaks).

chosen. As a first step, the length was decreased to $8.4 \mathrm{~cm}$ and the internal volume to $34 \mathrm{ml}$. In a second step, the internal volume was further decreased to $14 \mathrm{ml}$. The $14-\mathrm{ml}$ final internal volume was considered to be close to the practical limit, since drop formation, blockage of the outlet tube, and a consequent pulsation in the signal was observed if the spray chamber was not positioned perfectly. Similar conclusions were drawn by $\mathrm{Wu}$ and Taylor, regarding the volume of spray chambers $[29,30]$. The chromatographic outcome of this experiment is shown in Fig. 2. The resolution values are shown in the figure between the respective peaks. The resolutions between the 1st and 2nd and between the 2nd and 3rd peaks obtained with the smaller impact bead spray chamber were double those obtained with the double pass spray chamber.

\subsection{Chromatographic improvements due to mobile phase and column modifications}

Chromatographic conditions reported earlier for this application had some disadvantages [15]. The separation power at the beginning of the chromatogram was less than adequate (see Fig.
4). Thus the resolution and identification of early eluting peaks was not possible, particularly whenever one of them had a relatively higher concentration than the others. Since the beginning of the chromatogram is typically very crowded, important information could have been lost. The other major disadvantage was the low recovery of inorganic selenium compounds from the column, this being attributed to the interaction between the free silanol groups and the negatively charged selenium compounds. Under the original conditions, the $\mathrm{pH}$ resulting from the $0.1 \%$ TFA was 1.86. At that $\mathrm{pH}$, selenate exists with equal amounts of doubly and singly charged species [ $\mathrm{p} K_{\mathrm{a} 1}=$ (strong acid), $\mathrm{p} K_{\mathrm{a} 2}=1.92$ ], while selenite is in a partially single charged form $\left(\mathrm{p} K_{\mathrm{a} 1}=2.46\right.$, $\mathrm{p} K_{\mathrm{a} 2}=7.31$ ).

Decrease of the interaction between the inorganic compounds and the mobile phase was achieved by changing the stationary phase from a standard C-8 to the Waters Symmetry Shield modified C-8 phase. This reversed phase material is prepared by bonding of silica with 3-(chlorodimethylsilyl)propyl $N$-octylcarbamate [31]. The octylcarbamate phase shows reduced retention for polar and basic compounds because of the 
embedded carbamate group's weakening of the interaction between unbonded silanols and the analyte. The introduction of $\mathrm{NH}_{4} \mathrm{OH}$ to the mobile phase has a double advantage. The presence of hydroxide ions increases the $\mathrm{pH}$, allowing an increase in TFA concentration. The higher TFA concentration results in stronger ion pairing, moving the first organic selenium compound away from the inorganic peaks. The introduction of cations to decrease the silanol effect is a wellknown procedure. In this case the ammonia made a perfect match, since it did not introduce unnecessary anions. The use of $\mathrm{NH}_{4} \mathrm{OH}$ over $\mathrm{NaOH}$ is preferred because the former is more volatile. Fig. 3a shows the column recovery relationship of selenate and selenite over three orders of magnitude concentration range. Fig. $3 \mathrm{~b}$ shows the chromatogram of a $100-\mathrm{ng} / \mathrm{ml}$ selenate-selenite mix

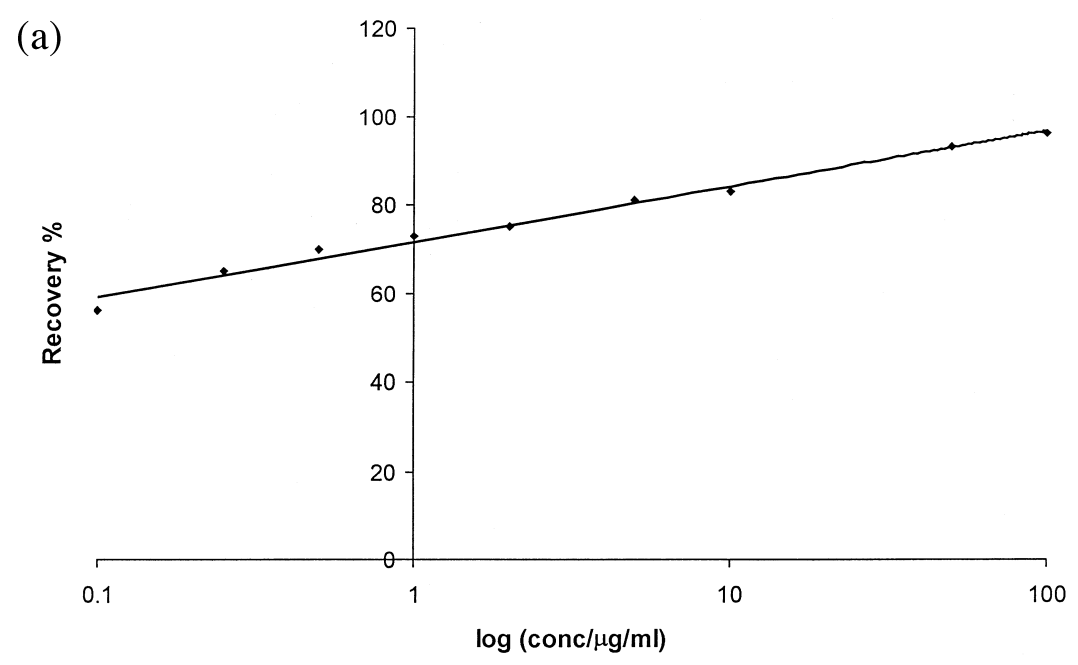

(b)

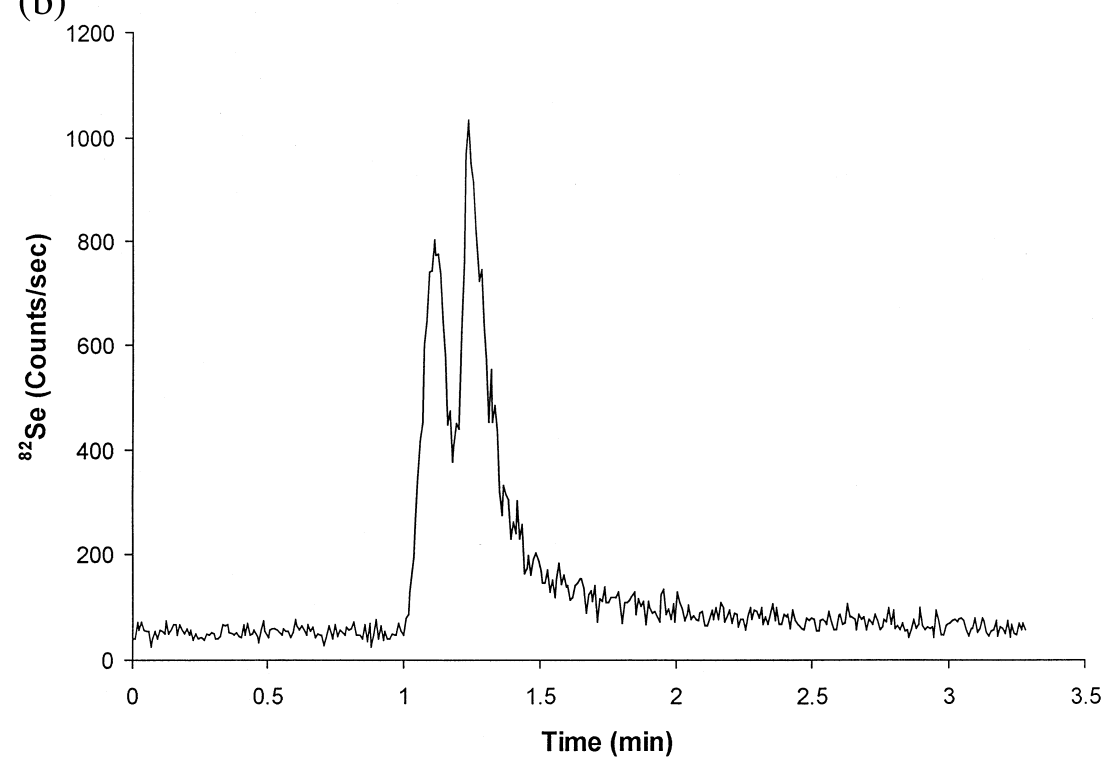

Fig. 3. (a) Logarithmic relationship between the column recovery percent and the sum of the selenate/selenite concentration using the Waters Symmetry Shield column. (b) Chromatogram of $100 \mathrm{ng} / \mathrm{ml}$ selenate/selenite using the Waters Symmetry Shield column $(\mathrm{S} / \mathrm{N}=15)$. 
with a $\mathrm{S} / \mathrm{N}=15$ (estimated from chromatogram). The logarithmic nature of the relationship between the column recovery percentage and the concentration of inorganic compounds is readily observable. The recovery of the standard mixture at the lowest concentration is approximately $60 \%$. Inorganic standards at this concentration were not detectable using the earlier ion pairing method. Quantitative determination of these peaks is feasible due to the logarithmic nature of the recovery plot. From the $\mathrm{S} / \mathrm{N}$ ratio of the response to the $100 \mathrm{ng} / \mathrm{ml}$ it is estimated that a $20-\mathrm{ng} / \mathrm{ml}$ standard could be quantified.

Another advantage of using the Waters Symmetry column with the modified mobile phase was the decreased retention times. The retention time of the last peak in the same standard mixture, compared with that obtained with the Zorbax column decreased from 21 to $15.5 \mathrm{~min}$, increasing its capacity factor from 12 to 14.5 . These seemingly opposite effects were due to two factors. Firstly, the void volume of the column decreased from $1.5 \mathrm{ml}$ to $1 \mathrm{ml}$, as a result of decreased diameter (from 4.6 to $3.9 \mathrm{~mm}$ ). This change would result in no capacity factor changes but a $30 \%$ decrease in retention times. The increase in capacity factors indicated that the Waters column was more retentive, attributable to a change in partition coefficient. Use of the modified mobile phase with the Zorbax column resulted in early separation efficiencies similar to those of the Symmetry column, but the retention time of the last eluting standard peak was $30 \mathrm{~min}$ and its capacity factor was 18 . An additional advantage of the Symmetry column is the possibility of using a mobile phase with $1 \%$ methanol content without the stationary phase physically collapsing. This is possible because of the polar modifier group, which connects the C-8 group with the silica base [31]. The minimized methanol content decreased the organic load on the ICP-MS, increasing its maintenance-free running time. For conventional ICP-MS operation, the TFA and the ammonia content of the mobile phase may seem high, but there was no observable salt deposition on the interface sample cones, due to the volatile nature of these compounds. Fig. 4 shows the comparison between the first four peaks of the standard mix-

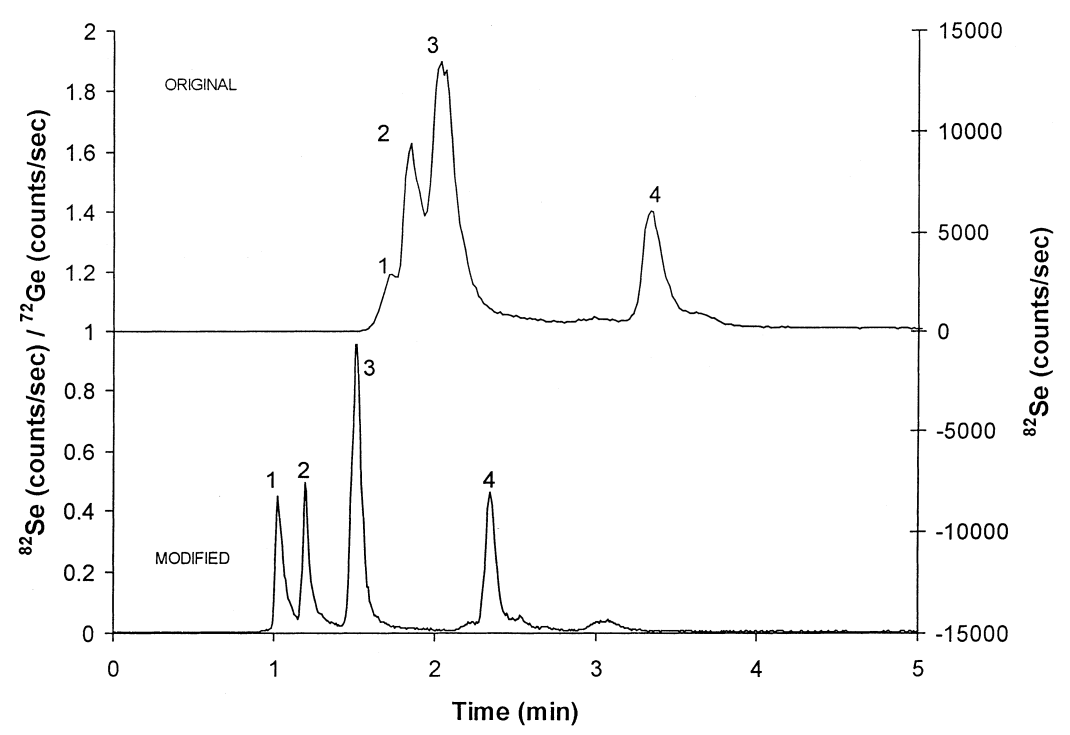

Fig. 4. Comparison of the chromatography of the first four peaks from the standard mixture under the Original, [Zorbax SB-C8 column $(4.6 \mathrm{~mm} \times 15 \mathrm{~cm})$, with Zorbax SB-C8 guard column $(4.0 \mathrm{~mm} \times 12.5 \mathrm{~mm}), 98 / 2(\mathrm{v} / \mathrm{v})$ water $/ \mathrm{methanol} \mathrm{with} 0.1 \%$ TFA as mobile phase (upper)], and under the Modified [5 $\mu \mathrm{m}$ Symmetry Shield RP8 (3.9 mm $\times 15 \mathrm{~cm})$ column, $99 / 1$ (v/v) water/methanol with $0.6 \%$ ( $\mathrm{pH}$ set to 2 with $\mathrm{NH}_{4} \mathrm{OH}$ ) as mobile phase (lower)] conditions: 1, selenate; 2, selenite; 3, DL-selenocystine; 4, Se-methyl-DL- selenocysteine. 
ture under the original and the modified conditions, including both chromatographic and spray chamber changes. It clearly shows the improvement under the modified conditions. The selenate and selenite are almost baseline separated from each other, and removed from the vicinity of the first selenoamino acid peak. This separation makes possible the determination of inorganic and organic molecules using the same chromatographic method, even when one of the early compounds is present in considerable excess.

The last, and distinctive, modification made to the method was the introduction of germanium as internal standard to the mobile phase, which had effect only on the stability of the instrument's calibration and not on the chromatographic separation. Thus the parameter monitored was not the intensity at $m / z=82$, but the ratio of the intensities at $m / z=82$ and 72 .

Table 1 shows the calibration properties of seven different selenoamino acids. All of the selenoamino acids calibration curves were linear, with correlation coefficient $(r)$ greater than 0.999 over three orders of magnitude, which was the range investigated. Comparison of $95 \%$ confidence intervals $(n=5)$ of the slopes of the selenoamino acid curves indicated significantly different responses for some of the selenoamino acids. The confidence intervals of the calibration curves of DL-selenocystine, Se-methyl-DL-selenocysteine, and $S e$-propyl-DL-selenocysteine showed no overlap with any other standard. The confidence intervals of the calibration curves of DLselenomethionine, $S e$-allyl-DL-selenocysteine, and DL-selenoethionine do overlap. The reason for these differences is unknown. The total selenium measurements of standards and the clarity of single standard injections did not indicate any discrepancies. The $95 \%$ confidence interval about the intercept included zero for all of the calibrations except those for DL-selenomethionine and DL-selenoethionine.

Unfortunately these results show that the instrument response factor for different selenoamino acids can vary by as much as $25 \%$. Thus, internal standardization can be used only for semi-quantitative analysis. The use of the spectroscopic internal standard was important since independent calibration was used. The calibration itself took $2 \mathrm{~h}$ and individual measurements took anywhere between 30 and $60 \mathrm{~min}$. Considering the time requirements of the calibration, it was highly desirable to keep the instrument drift and sensitivity fluctuations under control, and thus to use spectroscopic internal standardization. The internal standard could be introduced immediately before the nebulizer via a $\mathrm{T}$ connector, or the mobile phase itself could contain the spectroscopic internal standard. The latter method was more desirable, because it did not introduce additional column broadening and sample dilution, and could make the use of flow gradients possible. Comparison of chromatograms obtained with or without germanium in the mobile phase, indicates that there is no difference in separation or selenium signal intensity. Thus it is not necessary to have samples prepared in the mobile phase containing germanium. Signal intensities for peaks eluting in the dead volume are affected, however, if the sample was not pre-

Table 1

Calibration properties of seven selenoamino acids

\begin{tabular}{lllcrr}
\hline Compound & $\begin{array}{l}\text { Slope } \\
\text { counts } / \mu \mathrm{g} / \mathrm{ml}\end{array}$ & $\begin{array}{l} \pm 95 \% \text { C.I. } \\
\text { counts } / \mu \mathrm{g} / \mathrm{ml}\end{array}$ & Intercept & $\pm 95 \%$ C.I. & $r$ \\
\hline DL-Selenocystine & 0.08644 & 0.0022 & 0.000725 & 0.00808 & 0.999 \\
$S e$-methyl-DL-selenocysteine & 0.07592 & 0.0018 & 0.000957 & 0.00543 & 0.999 \\
DL-Selenomethionine & 0.06020 & 0.0015 & -0.01082 & 0.00744 & 0.999 \\
$S e$-allyl-DL-selenocysteine & 0.06117 & 0.0013 & -0.00136 & 0.00689 & 0.999 \\
$S e-1-$ propenyl-DL-selenocysteine & 0.05777 & 0.0013 & -0.000816 & 0.00349 & 0.999 \\
DL-Selenoethionine & 0.06090 & 0.0010 & -0.01013 & 0.00442 & 0.999 \\
$S e$-propyl-DL-selenocysteine & 0.06352 & 0.0010 & -0.00124 & 0.00493 & 0.999 \\
\hline
\end{tabular}




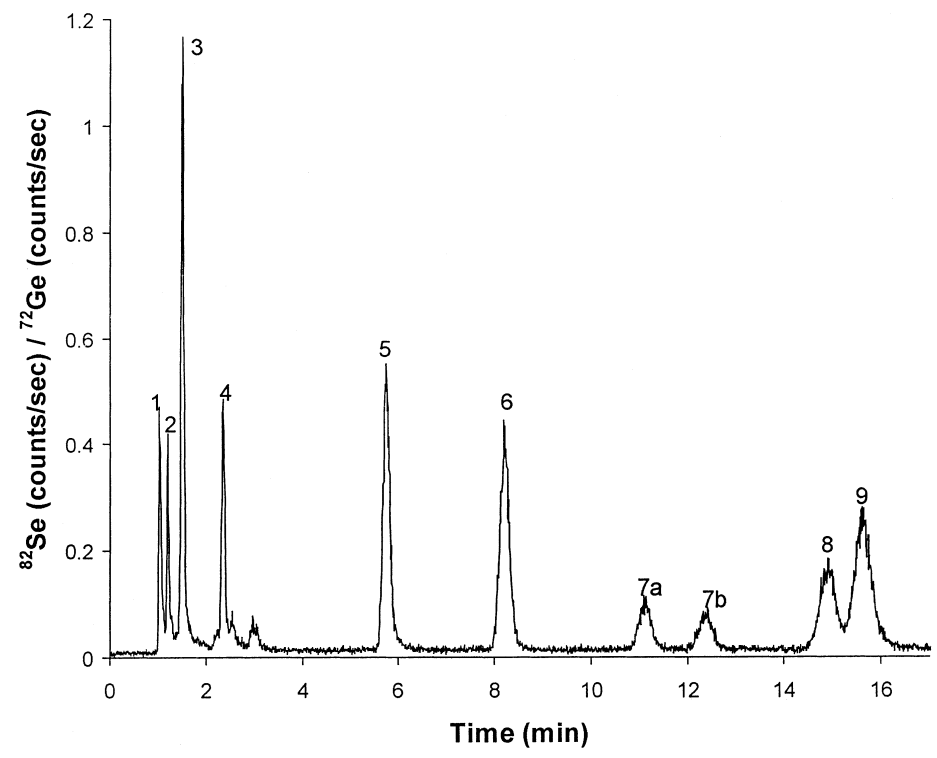

Fig. 5. Chromatogram of the full standard mixture using the modified conditions: 5, selenomethionine; 6, Se-allyl-DL-selenocysteine; 7a, cis-Se-1-propenyl-DL-selenocysteine; 7b, trans-Se-1-propenyl-DL- selenocysteine; 8, Se-1-propyl-DL-selenocysteine; 9, DLselenoethionine.

pared in the germanium-containing mobile phase, resulting in a negative peak in the germanium signal at the void volume. Thus the ratio of selenium to germanium signal for selenate eluting at the void volume would be artificially high and corrections would be necessary.

Fig. 5 shows the chromatogram of the standard mixture obtained with all the modifications in the chromatographic and spectroscopic parameters. The quality of a chromatographic separation can be evaluated by capacity factors, resolution, num- bers of theoretical plates and peak symmetry. Chromatographic factors for the modified method can be found in Table 2. Capacity factors were calculated for a void volume of $1 \mathrm{ml}$, ideally capacity factors between one and ten being desirable. The inorganic species and the DL-selenocystine were insufficiently retained according to this criterion. From the chromatogram (Fig. 5) it can be seen that most peaks were highly symmetrical. The peak asymmetry values $\left(A_{s}\right)$ were calculated by Peakfit ${ }^{\mathrm{TM}}$ software using the equation:

Table 2

Typical chromatographic factors for selenoamino acid standards using the Waters Symmetry column with the modified parameters

\begin{tabular}{|c|c|c|c|c|c|}
\hline Peak & Amino acid & $k^{\prime}$ & $R$ & $N$ & Asymmetry \\
\hline 1 & Selenate & 0.0 & & & 2.75 \\
\hline 2 & Selenite & 0.17 & 1.3 & & 1.56 \\
\hline 3 & DL-Selenocysteine & 0.5 & 2.9 & & 1.43 \\
\hline 4 & Se-methyl-DL-selenocysteine & 1.3 & 5.3 & 4754 & 1.08 \\
\hline 5 & DL-Selenomethionine & 4.7 & 13.3 & 6720 & 1.09 \\
\hline 6 & Se-allyl-DL-selenocysteine & 7.3 & 5.9 & 7401 & 1.08 \\
\hline $7 \mathrm{a}$ & cis-Se-1-propenyl-DL-selenocysteine & 10.2 & 5.6 & 7344 & 1.07 \\
\hline $7 \mathrm{~b}$ & trans-Se-1-propenyl-DL-selenocysteine & 11.5 & 1.9 & 8551 & 1.09 \\
\hline 8 & $S e$-propyl-DL-selenocysteine & 14 & 3.36 & 9334 & 1.07 \\
\hline 9 & DL-Selenoethionine & 14.5 & 0.98 & 8155 & 1.22 \\
\hline
\end{tabular}


Table 3

Instrumental limits of detection (LOD) and limits of quantification (LOD) of selenoamino acids

\begin{tabular}{lllll}
\hline Compound & $\begin{array}{l}\text { LOD } \\
(\mathrm{ng} / \mathrm{ml} \mathrm{Se})\end{array}$ & $\begin{array}{l}\text { LOD } \\
(\mathrm{ng} \mathrm{Se})\end{array}$ & $\begin{array}{l}\text { LOQ } \\
\text { (ng/ml Se) }\end{array}$ & $\begin{array}{l}\text { LOQ } \\
(\mathrm{ng} \text { Se) }\end{array}$ \\
\hline DL-Selenocystine & 5 & 0.05 & 20 & 0.20 \\
$S e$-methyl-DL-selenocysteine & 5 & 0.05 & 20 & 0.20 \\
DL-Selenomethionine & 10 & 0.10 & 30 & 0.30 \\
$S e$-allyl-DL-selenocysteine & 15 & 0.15 & 50 & 0.50 \\
DL-Selenoethionine & 20 & 0.20 & 80 & 0.80 \\
$S e$-propyl-DL-selenocysteine & 20 & 0.20 & 80 & 0.80 \\
\hline
\end{tabular}

$A_{s}=b / a$

for which ' $b$ ' is the width to the left of the peak mode and ' $a$ ' is the width to the right of the peak mode, each measured at $10 \%$ peak height. The values calculated for the first three peaks indicated tailing peaks, while the remaining peaks were symmetrical. These three peaks gave inflated efficiency values due to their asymmetry when the standard equation for $N$ was used and thus the values for them were not reported.

LOD and LOQ results are shown in Table 3. Detection and quantification limits were taken to be the concentrations corresponding to the mean of the blank plus three standard deviations of the blank, and the mean of the blank plus 10 standard deviations of the blank, respectively, as defined by IUPAC [32]. In the blanks, peaks were not observed, thus peak areas could not be obtained. The only measurable value was the baseline intensity and its standard deviation, which was in the units of counts/sec as for the peak heights. Consequently, peak height and not the peak area based calibrations were used for
LOD and LOQ calculations. The mean and the standard deviation of the blank were calculated for 100 points of the baseline. No limits are reported for cis / trans-Se-1-propenyl-DL-selenocysteine due to degradation of the standard. All other standards showed no degradation in solution in 18 months. As expected, later eluting species had higher limits of detection and quantification, as on-column band broadening reduces the height of the later eluting peaks. The concentration limits of detection and quantification are higher than some previously reported in the literature [16]. Absolute detection limits are similar to those reported, however, as other reports used injection volumes at least ten fold greater. Detection limits and quantification limits approximately three fold lower were obtained immediately after installation of a new electron multiplier detector (ETP) in the ICP-mass spectrometer. These improved results were due to both increased signal and decreased noise. After several weeks the limits approached the more typical values shown in Table 3.

Table 4

Quantitative and qualitative information on the enzymatic extract of phytoplankton $(n=1$, replicate analysis was not possible due to the limited available sample), Astragolus praelongus $(n=3)$, commercial selenium supplement $(n=3)$ and hot water extract of Nutrition 21 yeast $(n=3)^{\mathrm{a}}$

\begin{tabular}{lclllccc}
\hline Sample & $\begin{array}{l}\text { Total Se } \\
(\mu \mathrm{g} / \mathrm{g})\end{array}$ & $\begin{array}{l}\text { Extraction } \\
\text { efficiency } \\
(\%)\end{array}$ & $\begin{array}{l}\text { Column } \\
\text { recovery } \\
(\%)\end{array}$ & $\begin{array}{l}\text { Selenate } \\
(\mu \mathrm{g} / \mathrm{g})\end{array}$ & $\begin{array}{l}\text { Selenite } \\
(\mu \mathrm{g} / \mathrm{g})\end{array}$ & $\begin{array}{l}\text { Se-methyl-DL- } \\
\text { selenocysteine } \\
(\mu \mathrm{g} / \mathrm{g})\end{array}$ & $\begin{array}{l}\text { Selenometh- } \\
\text { ionine } \\
(\mu \mathrm{g} / \mathrm{g})\end{array}$ \\
\hline Phytoplankton & 2071 & 15 & 71 & 1.25 & 105 & 16 & 4 \\
Astragolus praelongus & $525 \pm 27$ & $93 \pm 6$ & $82 \pm 6$ & $1.3 \pm 0.3$ & $9.0 \pm 1.4$ & $48 \pm 2$ & $34 \pm 5$ \\
Commercial supplement & $592 \pm 10$ & $95 \pm 3$ & $99 \pm 5$ & $2.9 \pm 0.9$ & $482 \pm 22$ & - & $3.4 \pm 3$ \\
Nutrition 21 yeast & $1920 \pm 113$ & $8.5 \pm 1.2$ & $82 \pm 13$ & - & $10.7 \pm 1.6$ & $5 \pm 2$ & $23 \pm 5$ \\
\hline
\end{tabular}

\footnotetext{
${ }^{\mathrm{a}}$ The confidence intervals reflect $95 \%$ certainty.
} 

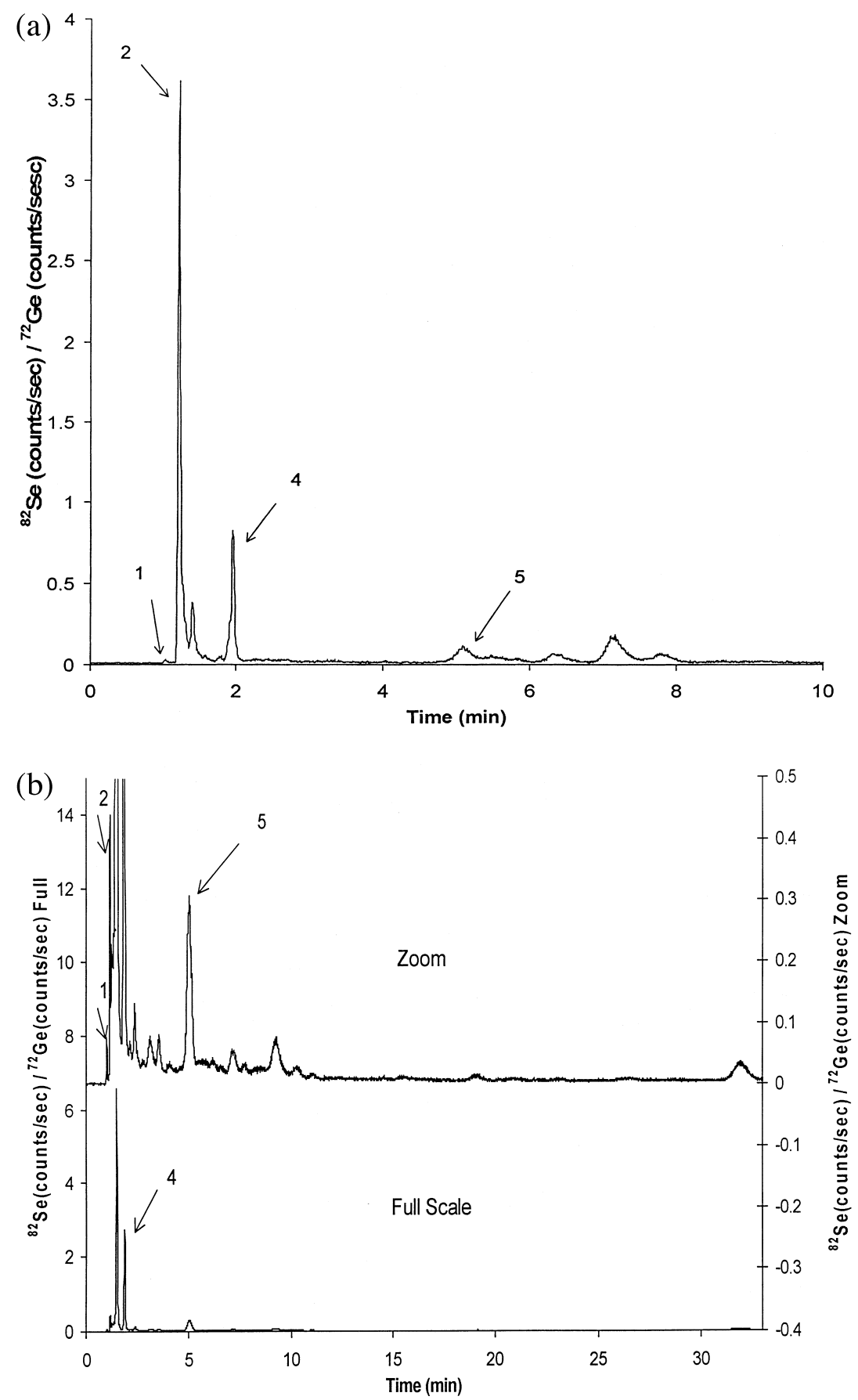

Fig. 6. Chromatogram of enzymatic extract of (a) phytoplankton, (b) Astragolus praelongus, (c) Vita Works selenium supplement and (d) hot water extract of Nutrition 21 yeast. 

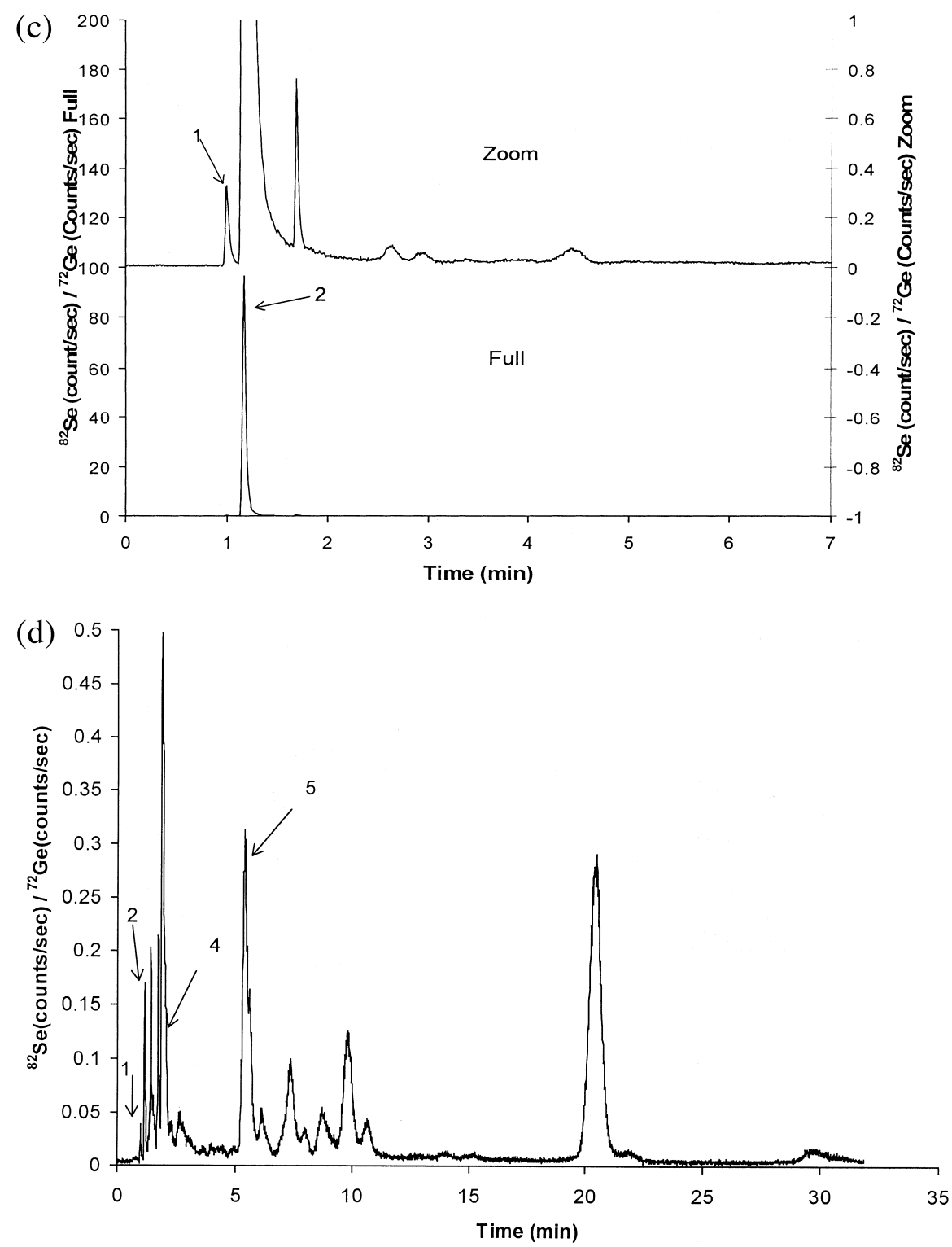

Fig. 6. (Continued)

Tables 1 and 3 contain data using the original mobile phase conditions, the modified chromatographic conditions showing similar results.

\subsection{HPLC-ICP-MS analysis of samples with enriched selenium content}

All samples were analyzed using the modified chromatographic conditions and most were also analyzed by comparison with the original parameters. Analyses of some of these samples by the original method were reported previously $[6,15]$. Aqueous extracts of selenium-enriched yeast samples reportedly contain compounds responsible for cancer prevention. The efficiency of water extraction is far lower than that of the enzymatic extraction, hence initial study of the latter was valuable to establish conditions. Chromatograms 
of different sample groups, using the modified chromatographic conditions, are shown in Fig. $6 \mathrm{a}-\mathrm{d}$. Qualitative and quantitative information for these samples are listed in Table 4. The differences in extraction efficiencies are clearly seen. The resistance of the phytoplankton sample towards the enzymatic extraction is not surprising, since the skeletal matrix makes it hard to work with. The poor efficiency of the hot water extraction compared to that the enzymatic technique reflects the readier peptide bond hydrolysis action of the enzyme.

Compound identification was confirmed only for selenate, selenite, selenomethionine, and $\mathrm{Se}$ methyl-DL-selenocysteine. The identified and quantified compounds account for only a small portion of the samples' selenium content (except for the supplement that had selenite as the major component). The total number of peaks found were 25, 22, 6, and 11 in the yeast, Astragalus praelongus, commercial nutrition supplement and phytoplankton, respectively. It was not possible to identify seleneocystine positively based solely on retention data, this being in line with other groups' findings for similar samples [33].

\subsection{Mass spectral analysis of standards by \\ electrospray ion trap mass spectrometry}

The lack of available standards to identify the selenium compounds with ICP-MS, based on their retention parameters, requires the use of supplementary techniques such as molecular mass spectrometry with electrospray ionization. An advantage of ICP-MS over MS is its elemental selectivity. ICP-MS analysis of complex LC eluents is relatively simple, since it can selectively detect selenium-containing molecules. Molecular MS, on the other hand, detects everything in the selected mass range, regardless of the selenium content, and yields complicated molecular structural information. Even so, in the case of selenium compounds, the profile of mass fragments containing one or two selenium atoms is recognizable from the characteristic selenium isotope ratios (Fig. 7). Before the application of HPLC-MS it was necessary to build a working knowledge of organic selenium MS using available standards. Sample electrospray spectra of some of these compounds are shown in Fig. $8 \mathrm{a}-\mathrm{d}$.

Molecules not containing $\mathrm{Se}-\mathrm{Se}$ bonds show similar initial fragmentation behavior. Selenocystine (Se-Se bond) fragments next to one of the selenium atoms, keeping the $\mathrm{Se}-\mathrm{Se}$ bond intact. The $\mathrm{SeSe}^{+}$ion is observable at $m / z=160$. The $\mathrm{M}^{+1}$ molecular ion is usually the most abundant species. The single selenium species loses a mass 17 fragment attributable to $\mathrm{NH}_{3}$. After the ammonia loss, the cysteine and the methionine

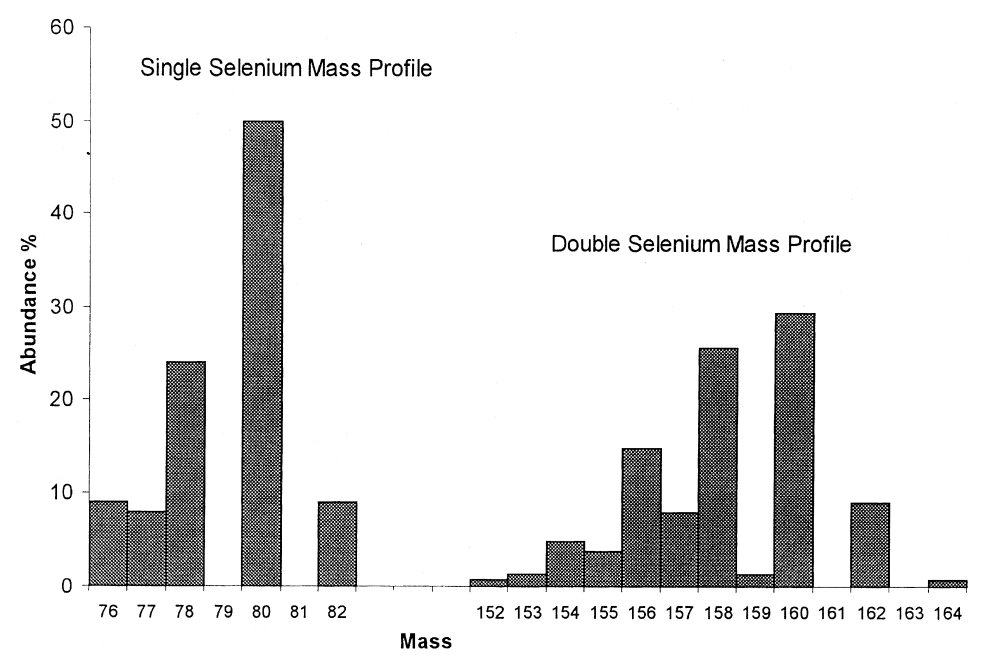

Fig. 7. Single and double selenium mass profiles. 
classes of molecules have clearly different fragmentation patterns. In the cysteine group, a parallel loss of $\mathrm{H}_{2} \mathrm{O}, \mathrm{CO}$ and $\mathrm{CO}_{2}$ is observable. In the methionine group there is a parallel loss of $\mathrm{H}_{2} \mathrm{O}, \mathrm{CH}_{2} \mathrm{O}$ and $\mathrm{CH}_{3} \mathrm{CHO}$ after the loss of $\mathrm{CO}$. Also a loss of $\mathrm{HCOOH}$ is observable parallel with the $\mathrm{NH}_{3}$ loss. The introduction of double bonds and side chains added interesting patterns to the fragmentation. More detailed fragmentation pat- terns are available for these compounds utilizing the MS/MS capability of the instrument and will be reported elsewhere [34].

Fig. 9a shows superimposed selected ion chromatographic (SIC) peaks obtained in a single HPLC-MS chromatogram of a standard mixture with selenoamino acid concentrations in the 5-10 $\mu \mathrm{g} / \mathrm{ml}$ range. Peaks 4, 5, 8, 9 indicate ions with $m / z=167,181$ 195, 195, respectively, which cor-
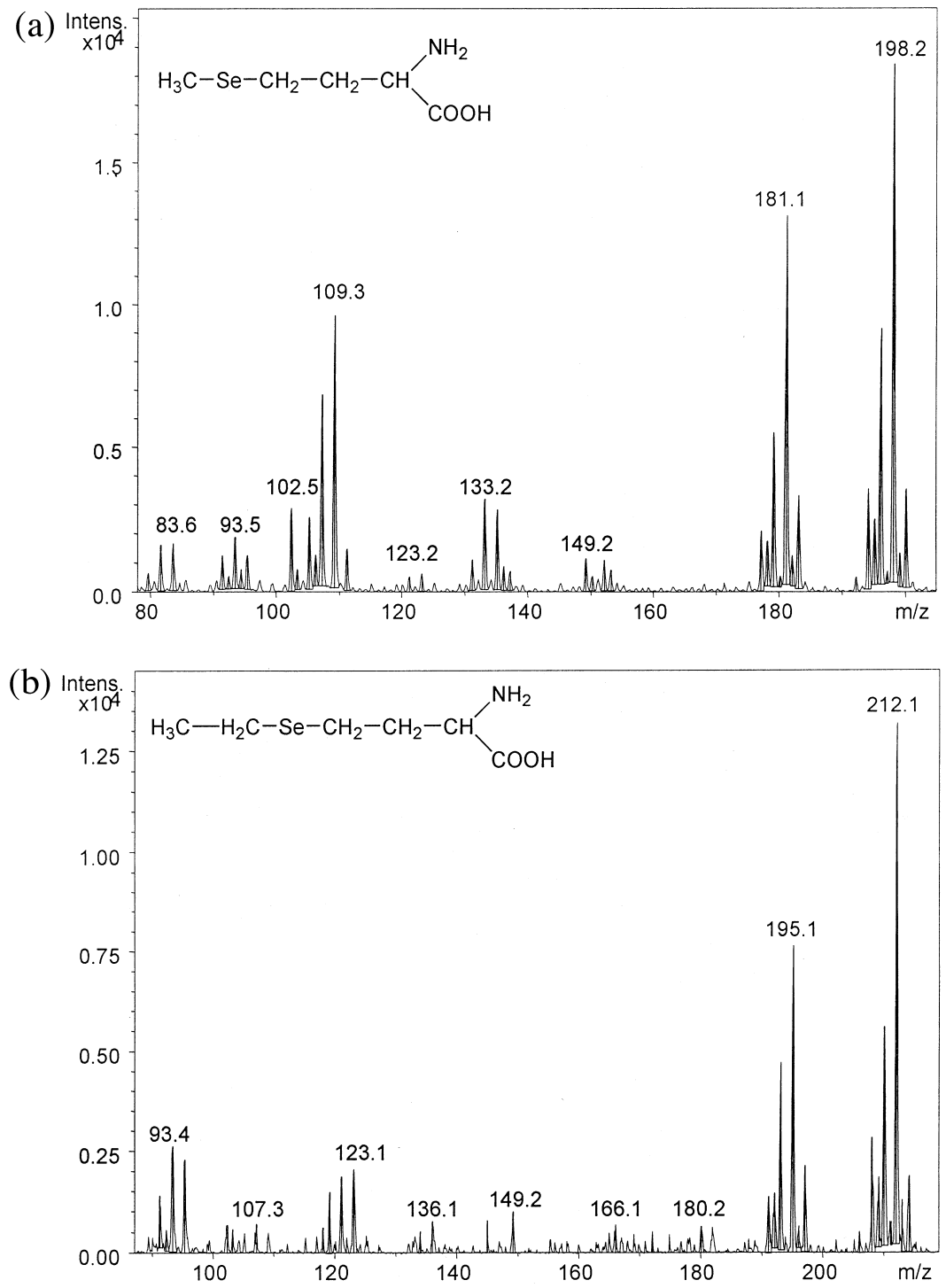

Fig. 8. Electrospray mass spectra of (a) DL-selenomethionine, (b) DL-selenoethionine, (c) DL-selenocystine and (d) Se-methyl-DLselenocysteine. 

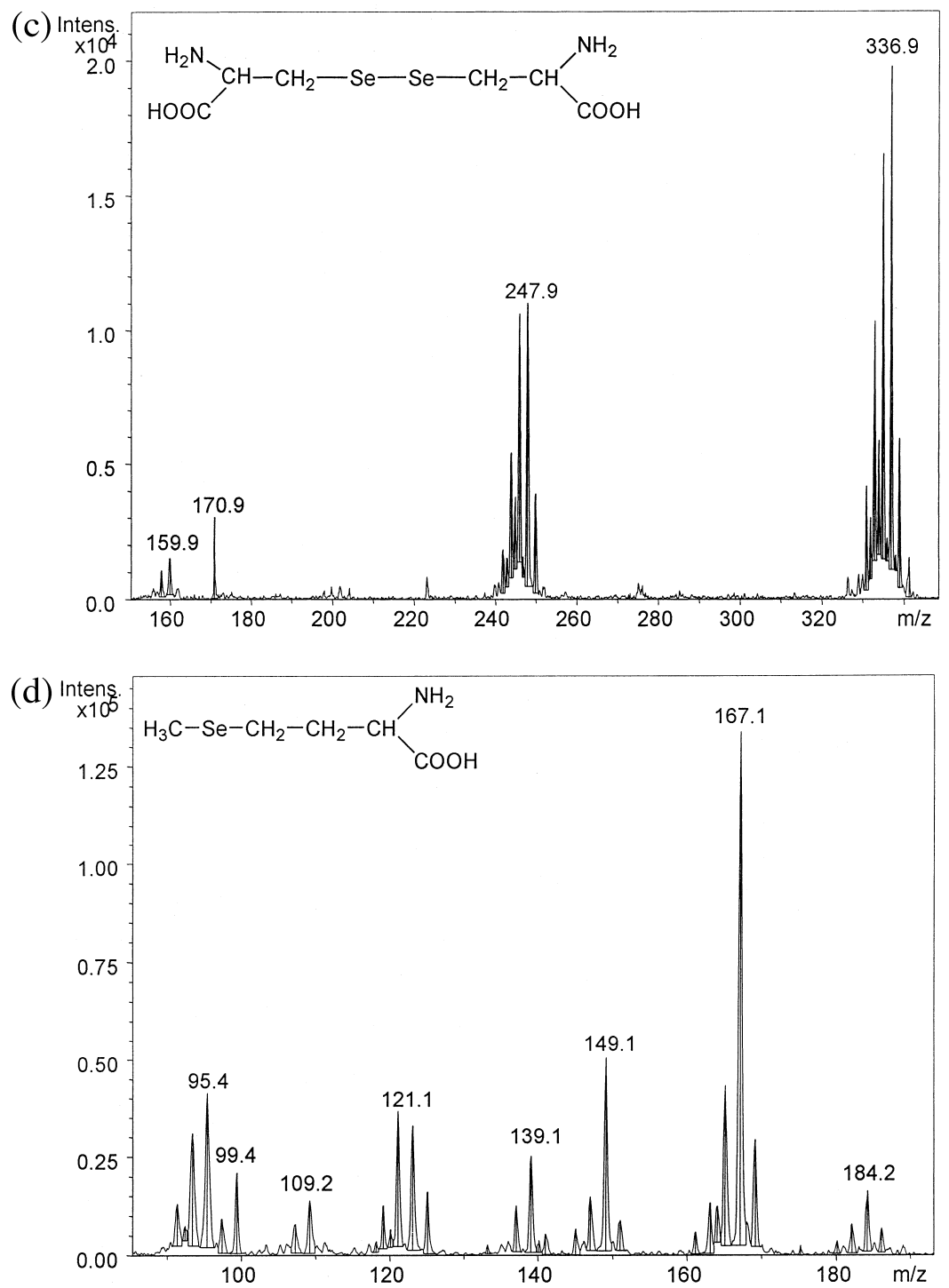

Fig. 8. (Continued)

respond to $\mathrm{M}^{+1}$ with the loss of ammonia ( $m=$ 17) in each case. Peak 9 is also depicted based on $m / z=212\left(\mathrm{M}^{+1}\right)$ SIC. Peaks $6,7 \mathrm{a}, 7 \mathrm{~b}$ are represented with SICs of $m / z=121$, which fragment was the most characteristic in their spectra. Fig. $9 \mathrm{~b}$ shows the mass spectra of peaks 4,5 and 6 summed over time intervals 5.14-5.31, 12.7513.11 and 18.69-19.08 min, respectively, background correction being also employed.

\section{Summary}

The improvements upon earlier chromatographic and hardware parameters led to much better separation power, sufficient to determine not only the later eluting compounds, but those that elute closer to the dead volume (even when one of those compounds is present at a much higher concentration). This improved separation 

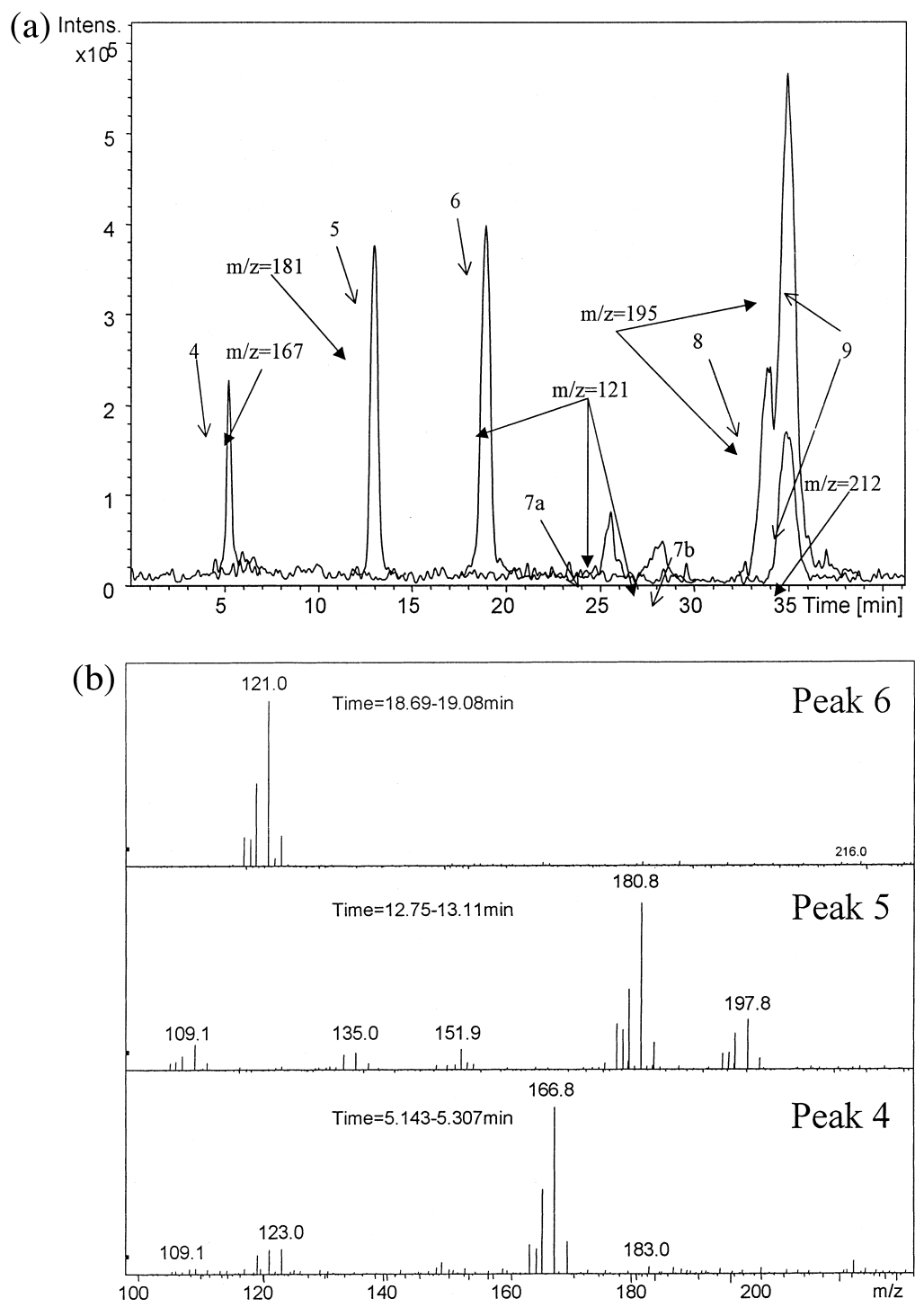

Fig. 9. (a) Superimposed selected ion chromatographic peaks obtained in a single HPLC-MS chromatogram of a standard. Peaks 4, 5, 6, 7a, 7b, 8 ions with $m / z=167,181,121,121,121,195$, respectively, and peak 9 indicates ions with $m / z=195$ and 212 . (b) HPLC-MS mass spectra of standards 4,5 and 6 summed over time intervals 5.14-5.31, 12.75-13.11 and 18.69-19.08 min, respectively.

did not require extended separation times, since Se-methyl-DL-selenocysteine elutes in 2.25 instead of $3.2 \mathrm{~min}$.

The presence of ammonia in the mobile phase had two advantages. It adjusted the $\mathrm{pH}$ to 2 allowing increased ion pairing agent concentration, and increased the recovery of the inorganic selenium compounds.

The decreased size of the spray chamber, from
$97 \mathrm{ml}$ to $14 \mathrm{ml}$, gave a factor of two improvement in resolution. Unfortunately the calibration curves from different selenoamino acids showed that compound independent calibration was not possible.

Analysis of the many different samples under the new parameters by HPLC-ICP-MS showed the presence of additional compounds in the earlier region of the chromatogram. Selenate, selen- 
ite, Se-methyl-DL-selenocysteine and selenomethionine were identified based on their retention indexes in the sample extracts.

The data collected with the electrospray mass spectrometer may allow the identification of unknown compounds in natural sample extracts and has already provided valuable and interesting information on the fragmentation patterns of different selenoamino acids. Compound identification in real samples using HPLC-ESI-MS could not be made at the present time due to low concentrations of the selenium compounds and interfering effect of spectra from other molecules. We continue our efforts to achieve identification of selenium compounds in selenium-enriched natural samples using organic mass spectrometry.

\section{Acknowledgements}

This work was supported in part by the NIH (CA45164) and the NRI Competitive Grants Program/USDA (Award No. 96-355003351). The provision of the Elan 5000 plasma source mass spectrometer by the Perkin-Elmer Corporation, and of the Symmetry Shield RP8 columns by Waters Chromatography Corp. are gratefully acknowledged. Eric Denoyer and Ray Crowley are thanked for their interest and assistance. The authors also thank John Gray (ETP) for providing the detector upgrade for the ICP-mass spectrometer. Any opinions, findings, and conclusions or recommendations expressed in this material are those of the authors and do not necessarily reflect the views of the specific granting agency.

\section{References}

[1] C. Ip, H. Ganther, in: L. Wattenberg, M. Lipkin, C.W. Boone, G.J. Kelloff (Eds.), Cancer Chemoprevention, CRC Press, Boca Raton, 1992, pp. 479-488.

[2] C. Ip, K. El-Bayoumy, H. Thompson, P. Upadhyaya, H. Ganther, S. Vandhanavikit, Comparative effect of inorganic and organic selenocyanate derivatives in mammary-cancer chemoprevention, Carcinogenesis 15 (1994) 187-192.

[3] L.C. Clark, B.W. Turnball, E.H. Slate, D.K. Chalker, J. Chow, L.S. Davis, R.A. Glover, D.K. Graham, E.G. Gross, A. Krongrad, J.L. Lesher, H.K. Park, B.B. Sanders, C.L. Smith, J.R. Taylor, D.S. Alberts, R.J.
Allison, J.C. Bradshaw, D. Curtus, D.R. Deal, M. Dellasega, J.D. Hendrix, J.H. Herlong, L.J. Hixon, F. Knight, J. Moore, J.S. Rice, A.I. Rogers, B. Schuman, E.H. Smith, J.C. Woodard, Effects of selenium supplementation for cancer prevention in patients with carcinoma of the skin - a randomized controlled trial, J. Am. Med. Assoc. 276 (1996) 1957-1963.

[4] J.M. Besser, J.N. Huckins, R.C. Clark, Separation of selenium species released from Se-exposed algae, Chemosphere 29 (1994) 771-780.

[5] G. Kolbl, Concepts for the identification and determination of selenium-compounds in the aquatic environment, Mar. Chem. 48 (1995) 185-197.

[6] P.C. Uden, S.M. Bird, M. Kotrebai, P. Nolibos, J.F. Tyson, E. Block, E. Denoyer, Analytical selenoamino acid studies by chromatography with interfaced atomic mass spectrometry and atomic emission spectral detection, Fresenius J. Anal. Chem. 362 (1998) 447-456.

[7] N. Gilon, A. Astruc, M. Astruc, M. Potin-Gautier, Selenoamino acid speciation using HPLC-ETAAS following an enzymatic hydrolysis of selenoprotein, Appl. Organomet. Chem. 9 (1995) 623-628.

[8] A.M. Rouhi, Plants to the rescue, Chem. Eng. News 75 (1997) 21-23.

[9] G. Dibo, Sequencing of Proteins and Peptides, Tempus Summer School, Budapest, 1992, p. M23.

[10] J. Janak, H.A.H. Billet, J. Frank, K. Luyben, P. Husek, Separation of selenium analogs of sulfur-containing amino-acids by high-performance liquid-chromatography and high-resolution gas-chromatography, J. Chromatogr. A 677 (1994) 192-196.

[11] A. Hagege, S. Niemczyk, M.J.F. Leroy, Separation of selenium compounds using HPLC-ICP-AES, Analusis 23 (1995) 476-479.

[12] T.A. Lei, W.D. Marshall, Selenium speciation by highperformance liquid-chromatography with online detection by atomic-absorption spectrometry, Appl. Organomet. Chem. 9 (1995) 149-158.

[13] J.M.G. Lafuente, M.L.F. Sanchez, A. SanzMedel, Speciation of inorganic selenium and selenoaminoacids by on-line reversed-phase high-performance liquid chromatography focused microwave digestion hydride generation atomic detection, J. Anal. At. Spectrom. 11 (1996) 1163-1169.

[14] N. Gilon, M. Potin-Gautier, M. Astruc, Optimization of the determination of inorganic and organic selenium species using high-performance liquid chromatographyelectrothermal atomic absorption spectrometry, J. Chromatogr. A 750 (1996) 327-334.

[15] S.M. Bird, P.C. Uden, J.F. Tyson, E. Block, E.R. Denoyer, Speciation of selenoamino acids and organoselenium compounds in selenium-enriched yeast using high-performance liquid chromatography inductively coupled plasma mass spectrometry, J. Anal. At. Spectrom. 12 (1997) 785-788.

[16] M.A. Quijano, A.M. Gutierrez, M.C. Perez Conde, C. Camara, Determination of selenocystine, selenomethio- 
nine, selenite and selenate by high-performance liquid chromatography coupled to inductively coupled plasma mass spectrometry, J. Anal. At. Spectrom. 11 (1996) 407-411.

[17] S. Cavalli, N. Cardellicchio, Direct determination of seleno-amino acids in biological tissues by anionexchange separation and electrochemical detection, J. Chromatogr. A 706 (1995) 429-436.

[18] U. Karlson, W.T. Frankenberger, Determination of gaseous Se-75 evolved from soil, Soil Sci. Soc. Am. J. 52 (1988) 678-681.

[19] K.T. Suzuki, M. Itoh, M. Ohmichi, Detection of selenium-containing biological constituents by high-performance liquid-chromatography plasma source-mass spectrometry, J. Chromatogr. B 666 (1995) 13-19.

[20] G. Zoorob, M. Tomlinson, J. Wang, J. Caruso, Evaluation of the direct-injection nebulizer in the coupling of highperformance liquid-chromatography to inductivelycoupled plasma-mass spectrometry, J. Anal. At. Spectrom. 10 (1995) 853-858.

[21] R.S. Houk, D.R. Wiederin, F.G. Smith, Direct injection nebulization for inductively coupled plasma mass-spectrometry, Anal. Chem. 63 (1991) 219-225.

[22] B.L. Sharp, Pneumatic nebulizers and spray chambers for inductively coupled plasma spectrometry - A review. 2. Spray chambers, J. Anal. At. Spectrom. 3 (1988) 939-963.

[23] C. Rivas, L. Ebdon, S. Hill, Effect of different spray chambers on the determination of organotin compounds by high-performance liquid chromatography-inductively coupled plasma mass spectrometry, J. Anal. At. Spectrom. 11 (1996) 1147-1150.

[24] K.M. Downard, K. Biemann, Methionine specific sequence ions by the dissociation of protonated peptides at high collision energies, J. Mass Spectrom. 30 (1995) 25-32.
[25] Z. Huang, J. Wang, D.A. Gage, J.T. Watson, C.C. Sweeley, Characterization of $N$-ethoxycarbonyl esters of amino acids by mass spectrometry, J. Chromatogr. 635 (1993) 271-281.

[26] R.J. Kraus, S.J. Foster, H.E. Ganther, Identification of selenocysteine in glutathione-peroxidase by mass-spectroscopy, Biochemistry 22 (1983) 5853-5858.

[27] H.E. Ganther, R.J. Kraus, S.J. Foster, Identification of selenocysteine by high-performance liquid chromatography and mass spectrometry, Methods Enzymol. 107 (1984) 582-592.

[28] E. Block, E.M. Calvey, C.W. Gillies, J.Z. Gillies, P.C. Uden, in: T. Johns (Ed.), Functionality of Food Phytochemicals, Vol. 31, Plenum Press, New York and London, 1997, pp. 1-30.

[29] M. Wu, G.M. Hieftje, A new spray chamber for inductively coupled plasma spectrometry, Appl. Spectrosc. 46 (1992) 1912-1918.

[30] K.A. Taylor, B.L. Sharp, D.J. Lewis, H.M. Crews, Design and characterization of a microconcentric nebuliser interface for capillary electrophoresis-inductively coupled plasma mass spectrometry, J. Anal. At. Spectrom. 13 (1998) 1095-1100.

[31] J.E. O'Gara, B.A. Alden, T.H. Walter, J.S. Petersen, C.L. Niedarlander, U.D. Neue, Simple preparation of a C8 HPLC stationary phase with an internal polar functional group, Anal. Chem. 67 (1995) 3809-3813.

[32] J.D. Winefordner, G.L. Long, Limit of detection, Anal. Chem. A 55 (1983) 712A-724.

[33] W. Goessler, D. Kuehnelt, C. Schlagenhaufen, K. Kalcher, M. Abegaz, K.J. Irgolic, Retention behavior of inorganic and organic selenium compounds on a silicabased strong-cation-exchange column with an inductively coupled plasma mass spectrometer as seleniumspecific detector, J. Chrom. A 789 (1997) 233-245.

[34] Kotrebai M. Work in progress. 